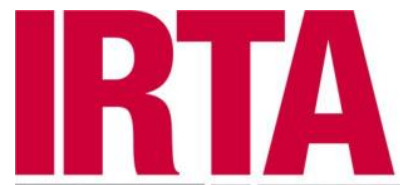

RIEGERTA I TECNOLOGIA

AGROALIMENTARIES

This document is a postprint version of an article published in Aquaculture $@$ Elsevier after peer review. To access the final edited and published work see https://doi.org/10.1016/i.aquaculture.2019.734210

Document downloaded from:

RTA Pubpro

Open dgital archive 
4

\section{Contrasting outcomes of Vibrio harveyi pathogenicity in gilthead seabream, Sparus aurata and European seabass, Dicentrachus labrax}

Authors: Joana Firmino ${ }_{1,2}{ }^{*}$, M. Dolores Furones ${ }_{1}$, Karl B. Andree ${ }_{1}$, Carmen Sarasquete ${ }_{3}$, Juan B. Ortiz-Delgado $_{3}$, Gloria Asencio-Alcudia $_{4}$, Enric Gisbert ${ }_{1}$

${ }^{1}$ IRTA, Centre de Sant Carles de la Ràpita (IRTA-SCR), Crta. Poble Nou km 5.5, 43540 Sant Carles de la Ràpita, Spain.

${ }^{2} \mathrm{PhD}$ programme in Aquaculture. Universitat Autònoma de Barcelona, 08193 Bellaterra, Spain.

${ }^{3}$ Instituto de Ciencias Marinas de Andalucía (ICMAN-CSIC), Universidad de Cádiz, Campus Universitario Río San Pedro, Puerto Real, Cádiz, Spain.

${ }^{4}$ Laboratorio de Acuicultura Tropical, División Académica de Ciencias Biológicas, Universidad Juárez Autónoma de Tabasco (DACBiol-UJAT), Villahermosa, Mexico.

*Corresponding Author: joana.firmino@irta.cat

+34977745427

${ }^{1}$ IRTA, Centre de Sant Carles de la Ràpita (IRTA-SCR), Crta. Poble Nou km 5.543540 Sant Carles de la Ràpita, Spain

0

1


32

Vibrio harveyi has been reported as the dominant heterotrophic bacterial species in western Mediterranean coastal areas during warm seasons, and is recognized as an economically significant pathogen for the aquaculture industry. The present work aimed to evaluate the pathogenicity of a $V$. harveyi strain isolated from ascitic fluid collected from cultured gilthead seabream and then used in a challenge experiment involving the two most important fish species in Mediterranean aquaculture: gilthead seabream, Sparus aurata and European seabass, Dicentrarchus labrax. The ascitic fluid from diseased juvenile seabreams, previously vaccinated against Photobacterium damselae and Vibrio anguillarum, was extracted and bacteria cultivated for isolation and characterization. Additionally, different tissues were sampled for histological evaluation and description. Significant histopathological responses were observed in hepatic and mucosal tissues. One of the strains isolated from ascitic fluid, IRTA 17-43, was selected for a bacterial challenge. Additionally, the attenuation of virulence through sequential passage of the strain on solid media was also assessed. In parallel, a co-habitation trial was performed in order to evaluate the possible transfer of the bacteria between injected and healthy individuals. Pathogenicity trials in gilthead seabream resulted in only $25 \%$ mortality when injected with $10^{7}$ CFU mL ${ }^{-1}$, whereas, for European seabass, a mortality of 95\% was recorded, with clear signs of vibriosis. When passed sequentially on solid media, the strain IRTA-17-43 showed a decrease of $35 \%$ in cumulative mortality for European seabass. No apparent transmission of the pathogen occurred during the co-habitation trial for both species. In conclusion, although few external signs of $V$. harveyi are observed in vaccinated carriers, internal effects of the infection were clear and severe. Although no horizontal transfer of infection was observed, the risk of occurrence between carriers and immunosuppressed individuals or between different species should be considered. This further validates that the establishment of a good health management system within fish farms is of major importance in order to avoid the onset of disease outbreaks. 
Vibrio spp. are ubiquitous in the marine environment, particularly in tropical and temperate waters, representing the major bacterial pathogens affecting development of fish farming (Austin and Austin, 2012; Vandenberghe et al., 2003; Zorrilla et al., 2003a), especially in the Mediterranean Sea (Pujalte et al., 2003a). One of the most commonly isolated marine Vibrio species, Vibrio harveyi [syn. V. carchariae] (Gauger and Gómez-Chiarri, 2002) is a marine Gramnegative bioluminescent bacteria with a requirement for sodium chloride (Farmer et al., 2005). The species has been described as free-living, associated to some microalgae blooms, or associated to the intestinal microbiota (Makemson and Hermosa, 1999; Miller et al., 2005; Ramesh et al., 1990). V. harveyi has also been reported during warm seasons, as the dominant heterotrophic bacterial species in western Mediterranean coastal areas (Arias et al., 1999; Ortigosa et al., 1994; Pujalte et al., 1999) and elsewhere, that can be present in expansive blooms (e.g. 15,400 km² of sea surface) in association with species of microalgae (Miller et al., 2005). Moreover, it is recognized as an economically significant pathogen for the aquaculture industry (Cano-Gomez et al., 2009), with some sporadic cases of wound infections in humans also reported (Austin, 2010; Del Gigia-Aguirre et al., 2017).

As a serious pathogen affecting the aquaculture industry $V$. harveyi has effected many marine vertebrate and invertebrates (Austin and Zhang, 2006), and is frequently isolated from marine bivalves with implications in some mass mortalities of shellfish (Pass et al., 1987; Sawabe et al., 2007; Travers et al., 2008). Additionally, some studies have described $V$. harveyi as pathogenic for several species of crustacean larvae (Diggles et al., 2000; Karunasagar et al., 1994; LavillaPitogo et al., 1990; Liu et al., 1996; Robertson et al., 1998; Vandenberghe et al., 1999). Moreover, it has also been associated to several opportunistic infections in fish, and responsible for several cases of infectious necrotizing enteritis, which is characterized by redness of the anal area, abdominal swelling with accumulation of ascitic fluid, inflammation of the anterior intestine and necrosis of the posterior intestine (Austin and Zhang, 2006). Several cultured fish species with economic relevance are globally affected, such as rainbow trout (Oncorhynchus mykiss), Atlantic salmon (Salmo salar L.) (Zhang and Austin, 2000), Senegalese sole (Solea senegalensis) (Zorrilla et al., 2003a), Japanese seabass (Lateolabrax japonicus) (Lee et al., 2002), cobia (Rachycentron canadum) (Liu et al., 2004b), common dentex (Dentex dentex) (Company et al., 1999; Pujalte et al., 2003b), among others.

Gilthead seabream, Sparus aurata and European seabass, Dicentrarchus labrax are presently the dominant fish species cultured along the Mediterranean coast (FAO, 2005-2018). Infections and 
mortality episodes observed in cultured seabream and seabass seem to be the result of the interaction of several factors such as poor water quality, seasonality, age-related host susceptibility, stress and pathogen virulence (Abdel-Aziz et al., 2013; Austin and Austin, 2012). Moreover, both fish species are often cultivated at the same farms or in very close proximity. Therefore, it is very relevant to assess the level of risk posed by pathogens, which are sharing tank facilities or where both fish species coexist in the same water masses.

Several bacterial species have been described as common pathogens in cultured gilthead seabream (Balebona et al., 1998; Rodgers and Furones, 1998; Toranzo et al., 2005). The genus Vibrio includes opportunistic pathogens that can affect cultured gilthead seabream (Balebona et al., 1998; Haldar et al., 2010) and European seabass (Pujalte et al., 2003b). Pujalte et al. (2003a) reported $V$. harveyi as the most frequent species recovered from diseased and asymptomatic gilthead seabream cultured in the Spanish Mediterranean area, from larval to commercial sizes. Disease outbreaks due to $V$. harveyi exhibit clear seasonal variation with increased prevalence coinciding with temperatures above $20^{\circ} \mathrm{C}$ (Arias et al., 1999; Pujalte et al., 1999) and it was also suggested that its increased prevalence could lead to co-infection of other bacterial pathogens (Pujalte et al., 2003a). Furthermore, in a recent study, Scarano et al. (2014) demonstrated that gilthead seabream reared in sea cages are a potential source of Vibrio spp. exhibiting resistance against the most commonly used antibiotics. Recently, in a survey assessing the main pathogens threatening aquaculture in the Mediterranean (Vendramin et al., 2016), $V$. harveyi was recognized as an emerging problem in seabass.

Although bacterial infections in fish farming systems are common, the present study was designed to determine and compare differences in susceptibilities of the two most important fish species in the Mediterranean aquaculture, Gilthead seabream (S. aurata) and European seabass (D. labrax), to a strain of Vibrio harveyi isolated from cultured seabream during a separate previous nutritional trial. This study aimed to assess the risk and the vulnerability of these two species to this strain of $V$. harveyi encountered in a naturally occurring epizootic event. Additionally, an attempt to attenuate virulence using serial passage on laboratory media was also performed to compare with the virulence observed using the native isolate. 


\subsection{Fish rearing conditions}

During October and November of 2017, over the course of a nutritional assay at IRTA facilities (Sant Carles de la Ràpita), located in the western Mediterranean (Tarragona, Spain), some isolated cases of abdominal swelling with an accumulation of ascitic fluid were observed in cultured juveniles of gilthead seabream (mean \pm SD; $15.0 \pm 0.5 \mathrm{~cm}$ length; mean body weight $81.3 \pm 3.8 \mathrm{~g}$ ), with a cumulative mortality of $3 \%$. Initially, fish were stocked in $200 \mathrm{~L}$ tanks at a density of $2 \mathrm{~kg} \mathrm{~m}^{-3}$ under environmental conditions of ambient photoperiod and water temperature $\left(18-22^{\circ} \mathrm{C}\right)$. Prior to their transport to IRTA, fish were routinely vaccinated the hatchery against Photobacterium damselae and Vibrio anguillarum. Three months after arrival, four diseased fish, showing clear signs of ascites and erratic swimming behavior, were collected to determine the etiology of the problem. Necropsy showed clear pathological signs of infection with severe inflammation of the digestive tract, predominantly in the posterior intestine and anus.

\subsection{Pathogen detection and identification}

For the bacteriological analysis, ascitic fluid was extracted aseptically with a syringe and plated onto Thiosulfate-citrate-bile salts-sucrose agar (TCBS) media and Trypticase Soy Agar (TSA) supplemented with $2.5 \% \mathrm{NaCl}$ (TSA 3\% final concentration). Plates were incubated at $23 \pm 1{ }^{\circ} \mathrm{C}$ for 48-72 h. After recovery of what appeared to be a pure bacterial culture on TCBS plates from ascitic fluid samples, colonies from plates, each corresponding to individual fish, were cultivated on TSA $3 \%$ at $23{ }^{\circ} \mathrm{C}$ for $48-72 \mathrm{~h}$ for purification and further characterization. Pure cultures of these isolates were characterized by Gram-staining and DNA sequencing (see below), then stored at $-80^{\circ} \mathrm{C}$ in glycerol (80\%) until further use. Samples from liver, spleen, digestive tract and gills were also collected and stored in buffered formalin 10\% for histological analysis (see below).

\subsection{Molecular characterization}

154 For identification of the bacterial isolates, DNA from pure cultures of four isolates from 155 seabream (one strain per fish) were extracted using DNeasy ${ }^{\circledR}$ Blood \& Tissue Kit (Qiagen) 156 following manufacturer's protocol. The DNA concentration and purity was quantified using a 
157 Nano-drop 2000 (Thermo Scientific). PCR amplifications were performed using the 16S-specific 158 primers Eub A and Eub B (Suzuki and Giovannoni, 1996) that amplify a region of $1600 \mathrm{bp}$ of the 159 16S rRNA. Using these primers, amplification was performed in $20 \mu \mathrm{L}$ reactions containing Taq polymerase buffer (1x), $0.5 \mathrm{U}$ of Taq polymerase, $\mathrm{MgCl}_{2}(2 \mathrm{mM})$, dNTP's $(900 \mu \mathrm{M})$, and $1 \mu \mathrm{M}$ of each primer. The amplification conditions included $5 \mathrm{~min}$ at $95^{\circ} \mathrm{C}$ followed by $30 \mathrm{~s}$ at $94{ }^{\circ} \mathrm{C}, 45 \mathrm{~s}$ at $48{ }^{\circ} \mathrm{C}$, and $1.5 \mathrm{~min}$ at $72{ }^{\circ} \mathrm{C}$ for 35 cycles, and terminating with a final extension cycle of $7 \mathrm{~min}$ at $72{ }^{\circ} \mathrm{C}$. PCR products were separated on a $1.2 \%(\mathrm{w} / \mathrm{v})$ agarose gel and visualized using ethidium bromide staining. Positive results were compared to a molecular weight standard (1Kb Plus DNA Ladder, Invitrogen) to assess molecular weight, then prior to sequence analysis, amplified DNA was purified using standard spin-column protocols described for the PCR Purification Kit (Ref\# 28104, Qiagen, Spain). Sequencing was performed by Sistemas Genómicos (Valencia, Spain). Tentative identity was established by a BLAST comparison of the sequence obtained to the $16 \mathrm{~S}$ rDNA data set in GenBank. Phylogenetic analysis was performed with 21 taxa and a total of 571 nucleotide positions in the final data set using Maximum Likelihood and Neighbor-Joining methods in MEGA X. In selecting taxa from GenBank for these analyses, sequences shorter than $600 \mathrm{bp}$, or sequences with numerous inconclusively determined nucleotides were excluded, whereas all positions containing gaps and missing data were eliminated. The evolutionary history was inferred by using the Maximum Likelihood method based on the Kimura 2parameter model. A discrete Gamma distribution was used to model evolutionary rate differences among sites [5 categories $(+G$, parameter $=0.3906)$.

For confirmation of the etiological agent, screening of both the infected fish, from the challenge experiments (see below) and from the original stock of diseased seabream $(n=10)$, was done using V. harveyi specific primers (Pang et al., 2006). Amplification was performed in $20 \mu \mathrm{L}$ reactions containing Taq polymerase buffer $(1 \times), 0.5 \mathrm{U}$ of Taq polymerase, $\mathrm{MgCl}_{2}(2 \mathrm{mM}), \mathrm{dNTP}$ 's $(900 \mu \mathrm{M})$, and $1 \mu \mathrm{M}$ of each primer specific for $V$. harveyi. The conditions for amplification were as follows: Initial denaturation of template DNA at $95^{\circ} \mathrm{C}$ for $10 \mathrm{~min}$, followed by 30 cycles of 1 min at $92{ }^{\circ} \mathrm{C}, 1 \mathrm{~min}$ at $55^{\circ} \mathrm{C}$, and $1 \mathrm{~min}$ at $72{ }^{\circ} \mathrm{C}$ with a final extension step of $7 \mathrm{~min}$ at $72{ }^{\circ} \mathrm{C}$. The presence of bands with a size of $382 \mathrm{bp}$ were considered as a positive result. Reactions lacking DNA, and containing genomic DNA of $V$. harveyi, were used as negative and positive controls, respectively. Visualization of PCR products was performed as described above. 
Moribund fish used for bacteria identification were also dissected and biopsies of different tissues (liver, gall bladder, posterior intestine, spleen and gills) were taken for the histological description of the impact of the pathogenic bacteria on the above-mentioned tissues. For this purpose, tissue samples were fixed in $10 \%$ buffered formalin (Scharlab S.L, Spain) then dehydrated in a graded series of ethanol (Scharlab S.L, Spain) (70-96\%), embedded in paraffin blocks and cut into serial sagittal sections (2-3 $\mu \mathrm{m}$ ) with a microtome (Leica RM2155, Germany). Sections were stained using Harris' haematoxylin and eosin. Photo-microscopy was performed and images analysed with a Leitz-Diaplan microscope (Wetzlar, Germany) coupled with a Spot Insight Color camera $(x 4, x 10, x 20)$.

\subsection{Biosecurity rearing conditions}

200

In order to test the potential virulence of the $V$. harveyi strain recovered from animals with abdominal swelling and an accumulation of ascitic fluid, a challenge test was designed. For this purpose, unvaccinated gilthead seabream and European seabass were obtained from a commercial hatchery located in the western Mediterranean and transported to IRTA facilities. Before the challenge, fish were stocked under quarantine conditions for 3 weeks and subjected to bacteriological analysis in order to validate their health status. Briefly, a random sample of 10 fish were screened to assess the absence of potential pathogens. Fish were euthanized with an overdose of MS-222, their head kidneys were sampled under aseptic conditions and individual samples swabbed onto TSA-NaCl and TCBS plates (incubated at $23 \pm 1^{\circ} \mathrm{C}$ for $48-72 \mathrm{~h}$ ). None of the TSA-NaCl and TCBS plates inoculated with seabass samples showed significant bacterial growth. There were a few isolated colonies that grew on TCBS and TSA-NaCl plates in $1 / 10$ gilthead seabream; these were tested for $V$. harveyi using specific PCR, but results were negative.

The bacterial challenge experiments were performed at IRTA's biosecurity room under level 2 biocontainment conditions in 32 cylindrical tanks (100 L), provided with water recirculation using an IRTAmar ${ }^{\circledR}$ RAS system (5-10\% renewal flow/day), including mechanical filtration and biofiltration, ultraviolet water treatment and chlorination, as well as ozone treatment of the outflow water. Stocking conditions were fixed at $32 \%$ of salinity at $21 \pm 1{ }^{\circ} \mathrm{C}$. The IRTAmar ${ }^{\circledR}$ RAS is controlled by Zenaqua ${ }^{\circledR}$ software. 
221 (www.randomizer.org) into fourteen tanks, with 50 fish per tank. For the seabass assay, four222 hundred-twenty fish (46.0 $\pm 8.8 \mathrm{~g})$ were randomly distributed into fourteen tanks with 30 fish per tank. Six experimental challenge conditions and a control group injected with PBS were established. Each experimental condition was tested in duplicate tanks. During the acclimation period, fish were fed ad-libitum with a commercial diet (50\% crude protein, $15 \%$ crude fat; MARPERLA MP-T, Skretting).

\subsection{Pathogenicity assay and co-habitation trial}

Based on results of a preliminary pathogenicity assay performed on juvenile (15 g) European seabass comparing all the isolates collected during the afore-mentioned nutritional assay (data not shown), one strain of $V$. harveyi isolated from seabream (reference\# IRTA-17-43) was selected for the virulence studies. Bacterial suspensions were prepared from inoculum grown on TSA-NaCl plates using the stock strains stored in glycerol at $-80{ }^{\circ} \mathrm{C}$. Cell suspensions were prepared to an O.D. $\lambda=550 \mathrm{~nm}$ of 0.6 , this being the density previously established by serial dilutions and plate counting as $10^{8}$ colony forming units (CFU) $\mathrm{mL}^{-1}$. This suspension was serially diluted ten-fold under sterile conditions, using sterile phosphate buffered saline (PBS), to prepare each dosage of bacterial inoculum to be used for the challenge by intraperitoneal injection. Prior to injection, fish were anaesthetized by immersion in tricaine methanesulfonate (MS-222, Sigma), then each fish was injected with $0.1 \mathrm{~mL}$ of bacterial suspension, comprising $10^{4}, 10^{5}, 10^{6}$ or $10^{7}$ CFU mL $\mathrm{m}^{-1}$ (50 fish per dose per tank in the case of seabream and 30 fish per dose per tank for seabass). In parallel, a co-habitation trial was performed in order to assess the possible transfer of the pathogenic bacteria between injected $\left(10^{7} \mathrm{CFU} \mathrm{mL} \mathrm{m}^{-1}\right)$ and healthy individuals within the same tank (1:1). Injected and non-injected fish were distinguished by caudal fin clipping of the non-injected fish. Furthermore, a last experimental group was injected with $10^{7} \mathrm{CFU} \mathrm{mL}{ }^{-1}$ of the same strain after it had been submitted to successive passages on solid media $(\times 7)$, to attenuate virulence through sequential passage outside the host. Two control groups were included: one intraperitoneally injected with PBS, and another control group for caudal fin clipping. Sampling of co-habitation individuals were performed before inoculation of co-habitant siblings $(T=0)$ and at 4, 24, 72 and 96 hours post-inoculation. Fish were fasted one day prior to inoculation and fed a commercial diet twice a day during the course of the experiment as already described. 
group. Mortality was recorded up to 15 days post-injection, with supervision of animals' condition every two hours, six times a day. When moribund animals were observed they were sacrificed with an overdose of MS-222 in order to avoid unnecessary suffering. At the end of the assay, all the remaining fish were sacrificed similarly. Confirmation of cause of death was determined by the recovery of the bacteria from head kidney samples cultured on TCBS and TSA-NaCl, and by specific PCR using DNA obtained from those bacterial colonies, as described above. Head kidney samples from survivors and asymptomatic fish were also plated on TCBS and TSA-NaCl media to check for pathogen presence and/or prevalence, and to evaluate the establishment of carrier-status of fish. Determination of the Lethal Dose $50 \%\left(L_{50}\right)$ was conducted by means of Probit analysis using the IBM SPSS Statistics 20.0 software.

All animal experimental procedures were conducted in according to the experimental research protocol approved by the Committee of Ethics and Animal Experimentation of the Institut de Recerca i Tecnologia Agroalimentàries and in agreement with the Guidelines of the European Union Council (86/609/EU) for the use of laboratory animals.

\section{Results}

\subsection{Pathogen characterization and identification}

All bacterial isolates from ascitic fluid of diseased gilthead seabream were Gram negative rods $(\sim 1.5 \mu \mathrm{m} \times 0.8 \mu \mathrm{m})$. On TSA-NaCl plates, colonies were pale cream-colored with a raised center and peripheral swarm rings. On TCBS agar media, the colonies appeared yellow with crenellated edges. The $16 \mathrm{~S}$ rDNA sequences were compared to the online database GenBank using the BLAST utility and multiple $V$. harveyi strains were identified as having identical sequences. From this result, the species was presumptively identified as Vibrio harveyi (Fig. 1). The confirmation of this was performed using species-specific PCR, which confirmed the isolates obtained as $V$. harveyi. From this point on, the strain IRTA 17-43 was designated as the challenge strain and use as a positive control for further screening of fish collected during the bacterial challenge trials (Fig. 2).

After the challenge, head kidney samples from recently dead or moribund individuals of both fish species were inoculated on TCBS media producing distinct bacterial colonies when recovered from each fish host species. Colonies from gilthead seabream appeared greyishgreen, whereas those recovered from European seabass were opaque yellow with clear sucrose degradation of the media. 


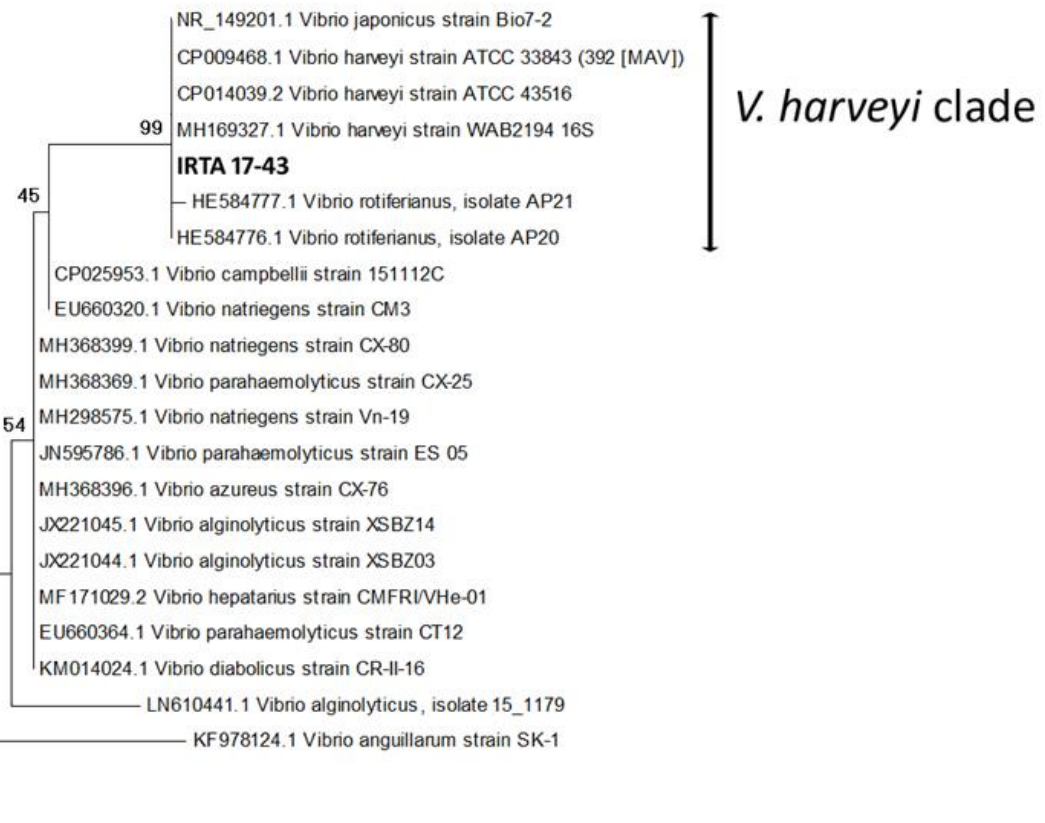

Figure 1. Phylogenetic relationship among IRTA 17-43 strain 16S rDNA sequence and others from the Vibrio genus. The scale for branch length (0.01 substitutions/site) is shown below the tree. The evolutionary history was inferred by using the Maximum Likelihood method based on the Kimura 2-parameter model. The tree with the highest log likelihood (-1124.5729) is shown. The percentage of trees in which the associated taxa clustered together is shown next to the branches.

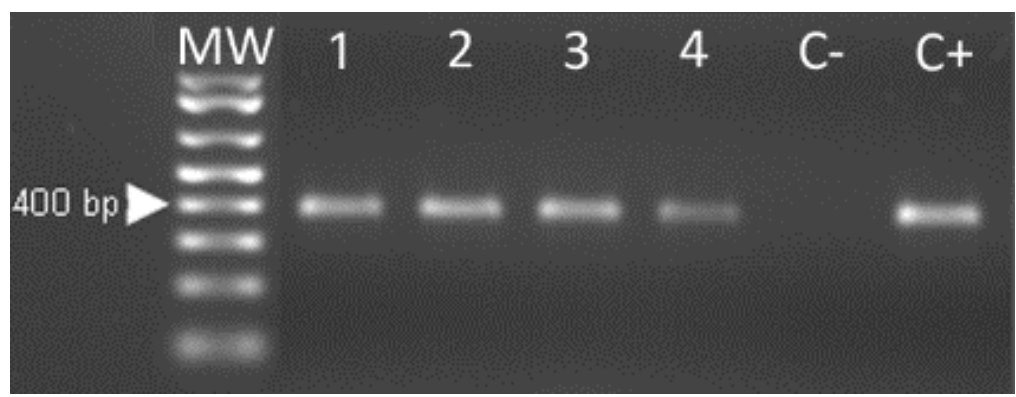

Figure 2. Examples of specific PCR (Pang et al., 2006) of bacterial colonies recovered from smears of head kidney from moribund fish. MW= molecular weight standard; Lanes 1-4 are samples recovered from moribund fish; $\mathrm{C}-=$ negative control lacking template $\mathrm{DNA} ; \mathrm{C}+=$ positive control genomic DNA from strain IRTA 17-43. 
301 The symptomatic juveniles of the diseased seabream showed a remarkable, generalized and severe congestion in the hepatic and branchial vascular systems (i.e, veins, arteries, sinusoids, capillaries, bile ducts). About $50 \%$ of the fish presented abdominal swelling, with accumulation of ascitic fluid, while congestion was less evident in the spleen and intestinal mucosa. In the hepatic parenchyma, numerous inclusions of haemosiderin, biliary pigments (i.e., lipofuscin, melanin, and haemosiderin pigments) and melanomacrophages were observed. In the hepatocytes, nuclear pyknosis and karyolysis, compatible with the development of necrotic processes, were observed (Fig. 3). Extravasations of blood (i.e, rupture of the wall of the capillaries), epithelial desquamations and aneurysms at the base of the gill epithelia were observed in diseased fish (Fig. 4a-d).

311 The gallbladder showed a remarkable enlargement and a strong hypertrophy of the muscle layer. As in the liver, the spleen also contained a large proportion of haemosiderin deposits, biliary pigments and melanomacrophages (Fig. 4e).

314 In the posterior intestine, a severe dilation of the intestinal- villi was observed, due to an 315 accumulation of inflammatory exudates, separating the mucosal and sub-mucosal layers. In the 316 intestinal mucosa of the diseased fish, there were signs of nuclear pyknosis, as well as a nuclear 317 depolarization of the absorptive cells or enterocytes, accompanied by a reduction in the number 318 of goblet cells (Fig. 4f- h). 

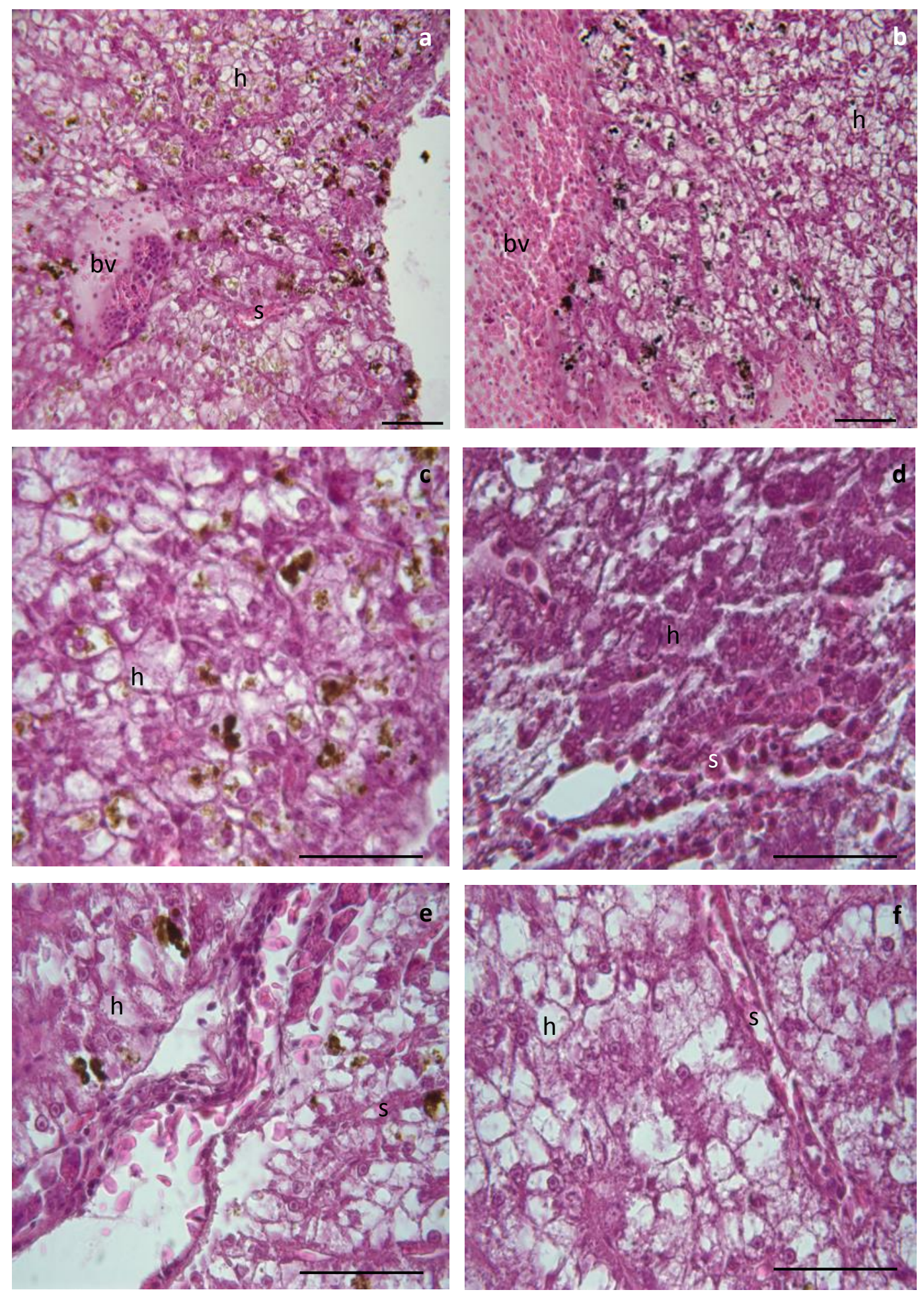

320 Figure 3. Liver from S. aurata specimens (a to $d$ correspond to fish 1 and e and $f$ correspond to

321 fish 2) infected with Vibrio harveyi showing congested blood vessels as well as hemosiderin

322 deposits (black precipitate) surrounding vasculature ( $a$ and $b$ ). Note accumulation of bile

323 pigment (yellow to light-brown deposits) within hepatic cytoplasm (c) and severe shrinkage of

324 hepatocyte cytoplasm with nuclear pyknosis and hepatocyte necrosis (d). Note also severely

325 congested hepatic sinusoids (d). From fish 2, hepatic parenchyma presented a moderate 
326 presence of hemosiderin deposits with vascular congestion by blood cells (e) as well as karyolisis

327 of the nucleus of hepatocytes and cellular necrosis (f). Scale bars represent $50 \mu \mathrm{m}$. bv: blood 328 vessel; h: hepatocyte; s: sinusoid. 

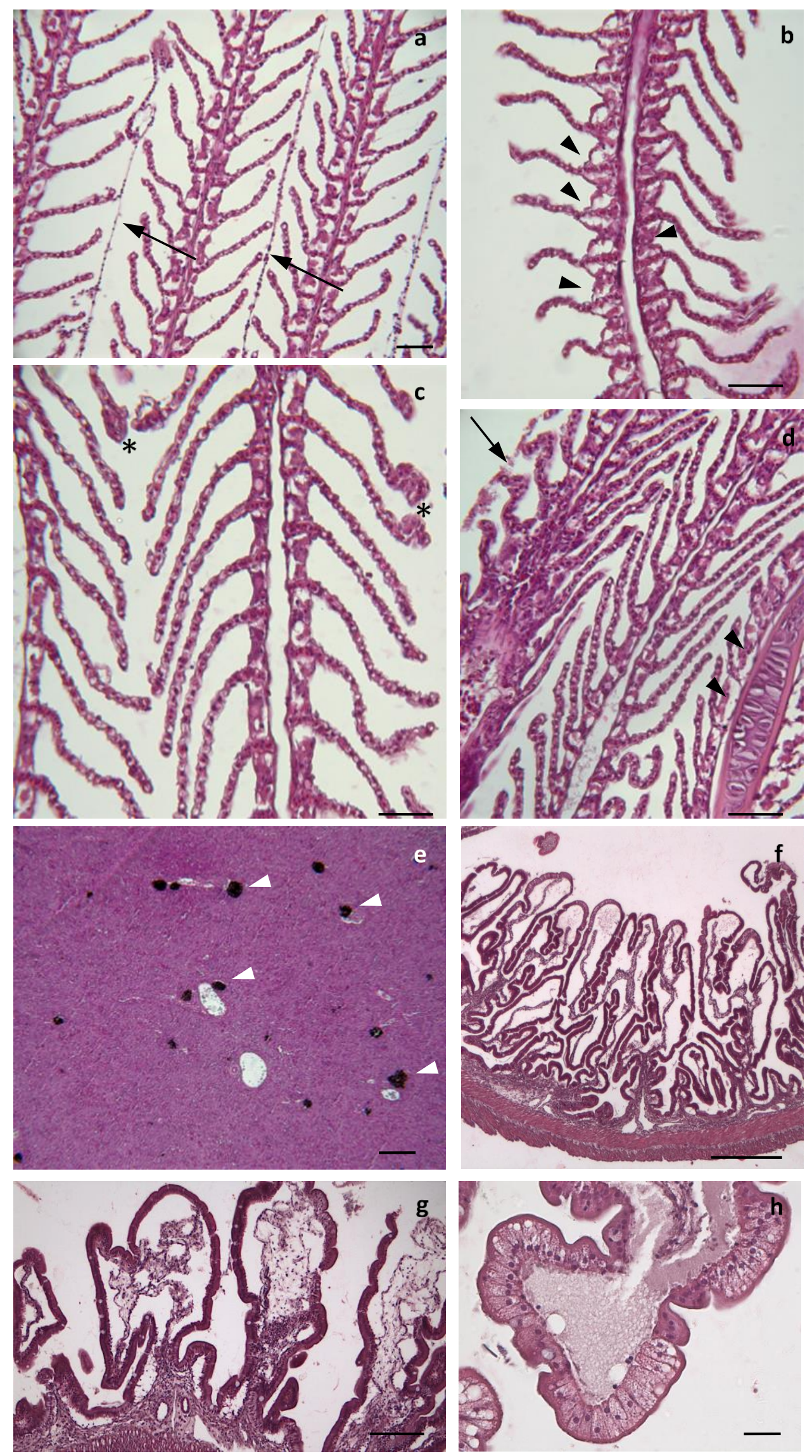
Figure 4. Gills from S. aurata specimens ( $a$ and $b$ from fish 1 and $c$ and $d$ from fish 2 ) infected with Vibrio harveyi showing congested capillaries as well as blood extravasation (arrows) (a) and epithelial desquamation of epithelium from gill filament (arrowheads) (b). Gills from specimen 2 showing aneurisms in the distal part of secondary lamellae (asterisk) (c) blood extravasation (arrow) as well as epithelial desquamation (arrowheads) (d). The spleen presented numerous melanomacrophage centers within splenic parenchyma (arrowheads) (e) whereas the intestine presented a severe dilation of the intestinal villi (f) and $(\mathrm{g})$, with noticeable presence of inflammatory exudates filling the lamina propria-submucosa space. Note also, distinctive nuclear pyknosis related with necrosis, as well as depolarization of the nucleus of the enterocytes. Scale bars represent $50 \mu \mathrm{m}$.

\subsection{Pathogenicity trials in gilthead seabream and European seabass}

Results of pathogenicity trials are shown in Figure 5. Mortality was moderate (25\%) in seabream injected with the highest dose of the bacteria $\left(10^{7} \mathrm{CFU} \mathrm{mL}{ }^{-1}\right)$; whereas for European seabass, a mortality of $95 \%$ was recorded in fish injected with the same inoculum dosage. Figure 6 showed a LD 50 of approximately $10^{6} \mathrm{CFU} \mathrm{mL^{-1 }}$ established for seabass, and predicted at $10^{9} \mathrm{CFU} \mathrm{mL}^{-1}$ for seabream. The majority of mortalities occurred within the first $48 \mathrm{~h}$ after inoculation. No mortality or clinical signs of bacterial infection were observed when fish were injected with the lower dose $\left(10^{4} \mathrm{CFU} \mathrm{mL}{ }^{-1}\right)$. After the fourth day post-inoculation until the end of the experiment, there were no more mortalities for either species.

In contrast to gilthead seabream that showed no clinical signs of infection, dead and moribund European seabass showed clear signs of vibriosis, such as external hemorrhages in the mouth, operculum and fins, and inflammation of the vent. For both species, moribund or dead fish that had been injected were confirmed to be positive for $V$. harveyi by plate cultivation and speciesspecific PCR.

The attenuated strain IRTA-17-43 (passed sequentially on solid media), showed a decrease of $35 \%$ in cumulative mortality for European seabass, whereas no differences in mortality were observed in the case of seabream (25\%). and healthy fish occurred, for both seabream and seabass. Non-infected fish did not die, presented no clinical signs, nor were positive for $V$. harveyi from head kidney necropsy samples. 

challenge were negative for $V$. harveyi.

\section{Seabream}

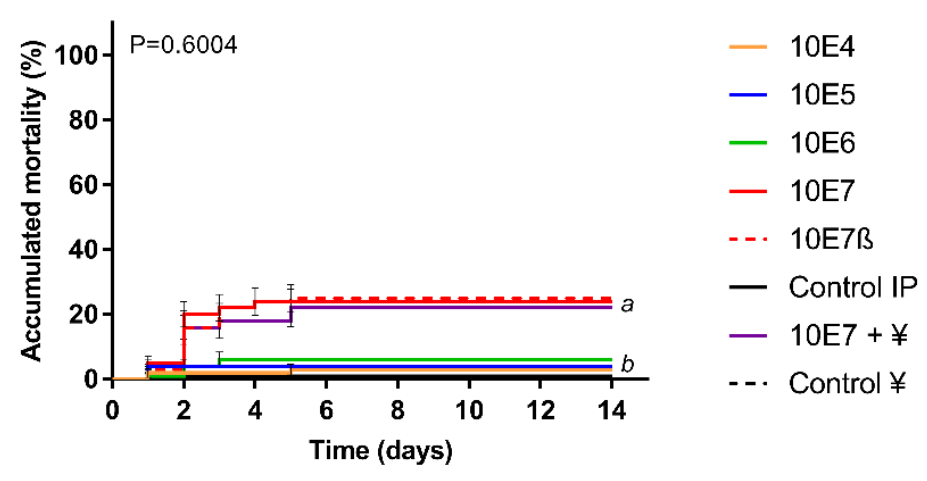

Seabass

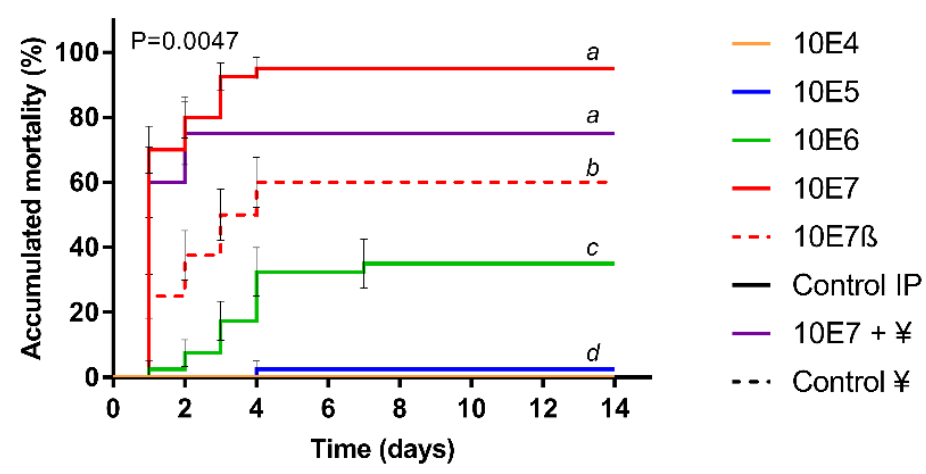

363

364 Figure 5. Accumulated mortality graph in percentage (\%) represented by mean values \pm standard

365 error, for gilthead seabream and European seabass intraperitoneally injected with $10^{4}, 10^{5}, 10^{6}$

366 and $10^{7} \mathrm{CFU} \mathrm{mL} \mathrm{m}^{-1}$ of the $V$. harveyi strain IRTA-17-43 during the 15 days pathogenicity assay

367 period. " $\beta$ " represents fish injected with the strain after successive passages on solid media $(\times 7)$.

368 Mortality of the injected fish from the co-habitation trial is represented by "10E7 + ¥", where

369 "¥" refers to non-injected individuals (fish with caudal fin clipping). Fish intraperitoneally

370 injected with PBS (control IP) and fish with caudal fin clipping control group (control $¥$ ) are both

371 represented and presented a $1 \%$ and $0 \%$ of accumulated mortality for seabream and seabass,

372 respectively. Log-rank test for comparisons of Kaplan-Meier mortality curves was applied and

373 different letters represent significant differences in mortality $(p<0.001)$. 

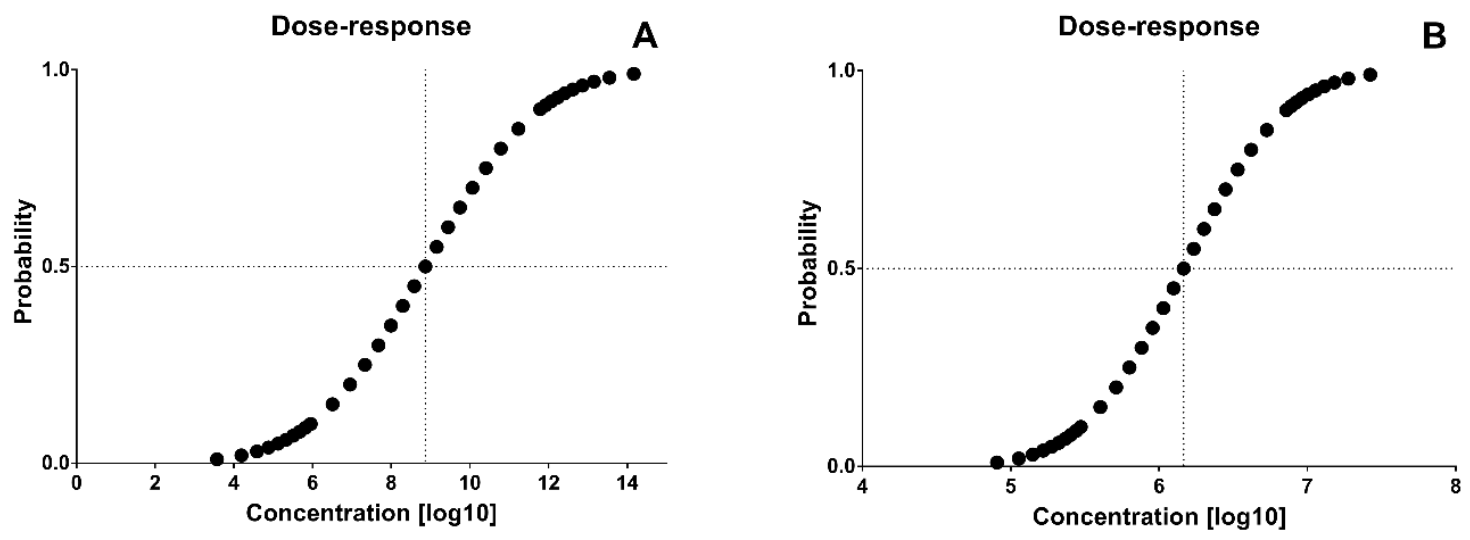

375

376

377

378

379

380

381

382

383

384

385

386

387

388

389

390

391

392

393

394

395

396

397

398

399

Figure 6. Log-Probit mortality graph for the gilthead seabream (A) and European seabass (B) intraperitoneally injected with $10^{4}, 10^{5}, 10^{6}$ and $10^{7} \mathrm{CFU} \mathrm{mL}^{-1}$ of the bacterial strain IRTA-17-43 of $V$. harveyi.

\section{Discussion}

Many of the mortalities described in seabreams cultured in the Mediterranean and Atlantic areas have been associated with epizootic events related to vibriosis, including etiology by $V$. harveyi. In general, this disease in intensive culture systems is characterized by systemic haemorrhagic septicemia with marked abdominal swelling. Internally, congested blood vessels, branchial, hepatic and intestinal hemorrhages and ascites are the most common histopathological signs of this bacterial disease in several species of cultured fish (Borrego et al., 2017).

A V. harveyi strain was recovered from ascitic fluid of several juvenile gilthead seabream (ca. 80 g), presenting abdominal swelling, which then was tested for virulence using intraperitoneal injection in the two most important farmed Mediterranean marine species, gilthead seabream and European seabass. This is not the first description of abdominal swelling in seabream larvae caused by V. harveyi and other Vibrio species (Sedano et al., 1996; Zorrilla et al., 2003b). There is no former description of these signs in seabream juveniles. However, signs of both ascites and gastroenteritis were also observed in cultivated juvenile cobia (Rachycentron canadum) infected with V. harveyi (Liu et al., 2004a) and V. alginolyticus (Liu et al., 2004b). In addition to abdominal swelling, important histopathological alterations were observed in fish infected with $V$. harveyi. Indeed, in symptomatic seabream specimens, characteristic histopathological responses of this vibriosis are observed, such as: abdominal swelling, with accumulation of viscous yellowishbloody fluids in the intestine and gall-bladder, or ascites in the body cavity, and severe and 
generalized congestion in a majority of the hepatic and branchial vascular systems (i.e, capillaries, sinusoids, bile ducts, etc.). The current results are similar to previous findings in many other fish species, such as seabass, among others (El-Sharaby et al., 2017; Korun and 403 Timur, 2008; Liu et al., 2004a; Sedano et al., 1996; Zorrilla et al., 2003b). It has been reported that the gastrointestinal tract is involved in the development of this epizootic disease, as a site of bacterial colonization and multiplication (Sedano et al., 1996). Haemosiderin deposits appear to be related to severe haemorrhage, leading to a release of hemoglobin, biliary derived pigments, etc., which can trigger defense mechanisms such as an increase in multifocal melanomacrophage centers in the spleen, liver, and kidney (Korun and Timur, 2008). These last authors indicated the presence of generalized haemorrhages in all organs and tissues, including the lateral musculature, with inflammatory infiltrations, and liquefactive necrosis in the renal tubules and hematopoietic tissue, leading to signs of anemia in fish infected with $V$. harveyi and other species of Vibrio. (El-Sharaby et al., 2017; Korun and Timur, 2008). Besides fish with obvious abdominal swelling, seabream presenting more mild signs seemed to be adapted to their condition with no additional pathological signs. It is important to note that while carrier fish appear to survive the infection, fish that reach market size displaying the more characteristic signs are not suitable for sale, which can contribute to considerable economical losses.

In our study, an apparently pure culture was obtained directly from the ascitic fluid of gilthead seabream, which suggests the signs of infection observed were due to a single aetiology. Our results contrasted with previous studies with gilthead seabream, where $V$. harveyi was usually recovered from diseased fish along with other specimens (Pujalte et al., 2003a; Pujalte et al., 2003b; Ramesh et al., 1990). The characterization of bacterial strain IRTA-17-43 was consistent with the current literature (Austin and Austin, 2012), exhibiting swarming motility on TSA medium, a behavior observed in other studies on V. harveyi (Lilley and Bassler, 2000; Pujalte et al., 2003b; Torky et al., 2016). Colony morphology and color are among the various key features that are usually unique to a particular genus of bacteria, serving as important criteria for bacterial preliminary identification. However, differences in colony color were observed on TCBS plates between bacteria recovered from gilthead seabream and European seabass after the challenge. In a study performed by Musa et al. (2008) with $V$. harveyi Isolated from black tiger shrimp (Penaeus monodon), both green and yellow colored colonies were observed in TCBS for different $V$. harveyi isolates, suggesting that isolates that exhibited yellow color on TCBS may be lacking the gene $\csc B$ that enable isolates to utilize sucrose. The fact that some Vibrio species like $V$. harveyi are variable in the utilization of sucrose from TCBS agar (Harris et al., 1996) might 
one purified strain was injected in both gilthead seabream and European seabass, it is interesting to find after the pathogenicity trial results a dissimilar phenotype is observed. The relevance of mutation and recombination for evolution of pathogens at both intra- and interhost levels was recently reviewed in Arenas et al. (2018). The mechanisms described would enable genetic variants of a pathogen to adapt to fast changing environments, escape the host immune system and might lead to resistance to chemotherapeutics. At a population level, such phenomena may produce the genetic diversity needed to initiate epidemics (Arenas et al., 2018). The mechanisms that drove the above-mentioned changes in colony shape and color due to their passage through two different fish species remain unexplained and deserve further investigation.

Additionally, $V$. harveyi strain IRTA-17-43 became attenuated after sequential passage on synthetic media ( $35 \%$ decrease in mortality in European seabass). Researchers conducting serialtransfer experiments have attributed the continual loss of pathogen virulence in the laboratory to Muller's ratchet mechanism (Bergstrom et al., 1999). Muller's ratchet model states that any clonally reproducing lineage, from viral or bacterial pathogen, will tend to accumulate deleterious mutations over time leading to the decrease of the mean fitness of the pathogen population as compared to the original population (Haigh, 1978). Our study supports a careful approach towards the use of bacterial strains from collections in experimental pathogenicity challenges, since prior frequent manipulation in the laboratory of origin may lead to false negative or inconclusive results.

The present study was in agreement with the previous results from Pujalte et al. (2003b), which reported pathogenicity for the first time for several strains of $V$. harveyi in European seabass. In fact, typical signs of classical septicemia induced by Vibrios (Toranzo et al., 2005) were also observed for injected European seabass in our study. Pujalte et al. (2003b) also described the low degree, or total absence, of virulence of some strains of $V$. harveyi for gilthead seabream, as we confirmed in our assays which showed lower mortalities obtained for seabream when compared with those of seabass. However, those results contrasted with those from Balebona et al. (1998) that reported a $\mathrm{LD}_{50}$ of $10^{5} \mathrm{CFU} \mathrm{g}^{-1}$ body weight for five $V$. harveyi strains assayed with gilthead seabream of 5-10 g. This disagreement between different studies demonstrates that, rather than $V$. harveyi being considered as a primary pathogen, this species acts as an opportunistic pathogen and/or its pathogenicity might be restricted in some strains (Pujalte et al., 2003a; Pujalte et al., 2003b). Although the virulence of the strain IRTA-17-43 was demonstrated, the original clinical signs of abdominal swelling were not reproduced. The observed abdominal swelling in this study was consistent with previous studies by Sedano et al. 
468 (1996) with gilthead seabream larvae orally inoculated using Vibrio strains, where it was 469 suggested that abdominal swelling could be a consequence of the host immune response, or 470 dependent on the route or dosage of infection. This lack of reproducibility of this specific pathogenic sign after bacterial challenge in our study may be either due to this latter effect since the intraperitoneal injection was not the same route of exposure as occurred originally, or due to the fact that a longer infection time may be needed to reproduce abdominal swelling and histological lesions in the liver, spleen, gut and gill filaments. Regarding survival, this study demonstrated that once fish were exposed to the bacterial challenge they succeed in eliminating the pathogen from their bodies. The immune mechanisms by which the host may have eliminated the pathogen are likely related to innate immune effectors (Uribe et al., 2011; Whyte, 2007), though this was outside the scope of this current work.

Although our results suggest that horizontal transfer between carrier and healthy animals seemed not to occur for strain IRTA-17-43, it is important to note that gilthead seabream that are asymptomatic carriers of $V$. harveyi may act as a reservoir of the pathogen that could lead to outbreaks when optimal conditions occur. More importantly from a risk analysis perspective, is susceptible fish species, like European seabass, which might be reared in the same farm and/or area, as is characteristic of the Mediterranean aquaculture, face an elevated risk from pathogen transmission due to their higher vulnerability to this bacteria, as demonstrated (Pujalte et al., 2003b). In the present study, no co-habitation trials were successful between both species, supporting previous studies. Although transmission between seabream and seabass did not occur using the dosage of $10^{7} \mathrm{CFU} \mathrm{mL} L^{-1}$, other dosages or different strains of $V$. harveyi may provide different results between the two host species.

In conclusion, the results of the present study were in agreement with previous data on gilthead seabream as a source of $V$. harveyi, as well as the virulence of this bacterium for European seabass. It was demonstrated that signs of carrier-status of $V$. harveyi might be difficult to identify since infected individuals present few external signs, although internal effects of the infection were clear and severe. Despite the fact that in the current study no direct transmission of the pathogen was observed between infected and healthy fish within the same species, it is not guaranteed that infection could not cross between carriers and immunosuppressed individuals, or between different species. Therefore, the importance of a good health management system within fish farms cannot be overstated in order to avoid the onset of disease outbreaks and emergence of new pathogens due to the intensification of production systems, antibiotic resistance and climate change. This is of special relevance for $V$. harveyi 
502

503

504

505

506

507

508

509

510

511

512

513

514

515

516

517

518

519

520

521

522

523

524

525

526

527

528

529

530

531

532

533

534

535

536

537

538

climate change (Baker-Austin et al., 2013). In this sense, this study contributes with updated information that can be applied to the essential risk analysis of the aquaculture sector, which can be further improved.

\section{Acknowledgements}

This work has been supported by the project "Nutritional strategies for the improvement of productive performance: the use of functional feeds and health diets in aquaculture (DIETAplus)", funded by JACUMAR (Ministry of Agriculture, Fisheries and Environment of Spain, MAPAMA ) and FEMP (EU), and the MedAID project (Grant agreement No 727315), funded by the European Union's Horizon 2020 research and innovation program. Joana P. Firmino have been subsidized by the Industrial PhD program of the Generalitat de Catalunya and TECNOVITFARMFAES.

The authors declare that there are no conflicts of interest.

\section{References}

Abdel-Aziz, M., Eissa, A.E., Hanna, M., Okada, M.A., 2013. Identifying some pathogenic Vibrio/Photobacterium species during mass mortalities of cultured Gilthead seabream (Sparus aurata) and European seabass (Dicentrarchus labrax) from some Egyptian coastal provinces. International Journal of Veterinary Science and Medicine 1, 87-95.

Arenas, M., Araujo, N.M., Branco, C., Castelhano, N., Castro-Nallar, E., Pérez-Losada, M., 2018. Mutation and recombination in pathogen evolution: Relevance, methods and controversies. Infection, Genetics and Evolution 63, 295-306.

Arias, C.R., Macián, M.C., Aznar, R., Garay, E., Pujalte, M.J., 1999. Low incidence of Vibrio vulnificus among Vibrio isolates from sea water and shellfish of the western Mediterranean coast. Journal of Applied Microbiology 86, 125-134.

Austin, B., 2010. Vibrios as causal agents of zoonoses. Veterinary Microbiology 140, 310-317.

Austin, B., Austin, D.A., 2012. Vibrionaceae Representatives, In: Bacterial Fish Pathogens: Disease of Farmed and Wild Fish. Springer Netherlands, Dordrecht, 357-411.

Austin, B., Zhang, X.H., 2006. Vibrio harveyi: a significant pathogen of marine vertebrates and invertebrates. Letters in Applied Microbiology 43, 119-124. 
Balebona, M.C., Zorrilla, I., Moriñigo, M.A., Borrego, J.J., 1998. Survey of bacterial pathologies 540 affecting farmed gilt-head sea bream (Sparus aurata L.) in southwestern Spain from 1990 to 541 1996. Aquaculture 166, 19-35.

Bergstrom, C.T., McElhany, P., Real, L.A., 1999. Transmission bottlenecks as determinants of virulence in rapidly evolving pathogens. Proceedings of the National Academy of Sciences 96, 5095-5100.

Borrego, J.J., Labella, A.M., Castro, D., Ortiz-Delgado, J.B., Sarasquete, C., 2017. Updated of the Pathologies Affecting Cultured Gilthead Seabream, Sparus aurata. Annals of Aquaculture and Research 4, 1033.

Cano-Gomez, A., Bourne, D.G., Hall, M.R., Owens, L., Høj, L., 2009. Molecular identification, typing and tracking of Vibrio harveyi in aquaculture systems: Current methods and future prospects. Aquaculture 287, 1-10.

Company, R., Sitj, A., Pujalte, M.J., Garay, E., Alvarez-Pellitero, P., P, J., 1999. Bacterial and parasitic pathogens in cultured common dentex, Dentex dentex L. Journal of Fish Diseases 22, 299-309.

Del Gigia-Aguirre, L., Sánchez-Yebra, W., García-Muñoz, S., Rodríguez-Maresca, M., 2017. First description of wound infection with Vibrio harveyi in Spain. New Microbes and New Infections 19, C.

Diggles, B.K., Moss, G.A., Carson, J., Anderson, C.D., 2000. Luminous vibriosis in rock lobster Jasus verreauxi (Decapoda: Palinuridae) phyllosoma larvae associated with infection by Vibrio harveyi. Diseases of Aquatic Organisms 43, 127-137.

El-Sharaby, S.M.A., Abd-Elgaber, M., Tarabees, R., Khalil, R.H., Ali, M.N., El-ballal, S., 2017. Bacteriological and Histopathological Studies on Vibrio Species Isolated from Naturally Infected Freshwater Fish in Delta Region, Egypt. Advances in Animal and Veterinary Sciences 6 (1), 17-26.

FAO, 2005-2018. National Aquaculture Sector Overview. Visión general del sector acuícola nacional - España. National Aquaculture Sector Overview Fact Sheets. Texto de De la Figuera Morales, R. In: Departamento de Pesca y Acuicultura de la FAO. Roma.

Farmer, J.J., Janda, M., Brenner, F.W., Cameron, D.N., Birkhead, K.M., 2005. Bergey's Manual ${ }^{\circledR}$ of Systematic Bacteriology : Volume 2: The Proteobacteria, Part B: The Gammaproteobacteria. Springer, New York.

Gauger, E.J., Gómez-Chiarri, M., 2002. 16S ribosomal DNA sequencing confirms the synonymy of Vibrio harveyi and V. carchariae. Diseases of Aquatic Organisms 52, 39-46.

Haigh, J., 1978. The accumulation of deleterious genes in a population-Muller's Ratchet. Theoretical Population Biology 14, 251-267.

Haldar, S., Maharajan, A., Chatterjee, S., Hunter, S.A., Chowdhury, N., Hinenoya, A., Asakura, M., Yamasaki, S., 2010. Identification of Vibrio harveyi as a causative bacterium for a tail rot disease of sea bream Sparus aurata from research hatchery in Malta. Microbiological Research 165, 639648. 
Harris, L., Owens, L., Smith, S., 1996. A selective and differential medium for Vibrio harveyi. Applied and Environmental Microbiology 62, 3548-3550.

Karunasagar, I., Pai, R., Malathi, G.R., Karunasagar, I., 1994. Mass mortality of Penaeus monodon larvae due to antibiotic-resistant Vibrio harveyi infection. Aquaculture 128, 203-209.

Korun, J., Timur, G., 2008. Marine Vibrios associated with diseased sea bass (Dicentrarchus labrax) in Turkey. Journal of Fisheries Sciences 2 (1), 66-76.

Lavilla-Pitogo, C.R., Baticados, M.C.L., Cruz-Lacierda, E.R., de la Pena, L.D., 1990. Occurrence of luminous bacterial disease of Penaeus monodon larvae in the Philippines. Aquaculture 91, 1-13.

Lee, K.K., Liu, P.C., Chuang, W.H., 2002. Pathogenesis of gastroenteritis caused by Vibrio carchariae in cultured marine fish. Marine Biotechnology 4, 267-277.

Lilley, B.N., Bassler, B.L., 2000. Regulation of quorum sensing in Vibrio harveyi by LuxO and sigma-54. Molecular microbiology 36, 940-954.

Liu, P.C., Lee, K.K., Yii, K.C., Kou, G.H., Chen, S.N., 1996. News \& Notes: Isolation of Vibrio harveyi from Diseased Kuruma Prawns Penaeus japonicus. Current Microbiology 33, 129-132.

Liu, P.C., Lin, J.Y., Chuang, W.H., Lee, K.K., 2004a. Isolation and Characterization of Pathogenic Vibrio harveyi (V. carchariae) From the Farmed Marine Cobia Fish Rachycentron canadum L. with Gastroenteritis Syndrome. World Journal of Microbiology and Biotechnology 20, 495-499.

Liu, P.C., Lin, J.Y., Hsiao, P.T., Lee, K.K., 2004b. Isolation and characterization of pathogenic Vibrio alginolyticus from diseased cobia Rachycentron canadum. Journal of Basic Microbiology 44, 2328.

Makemson, J.C., Hermosa, G.V., 1999. Luminous bacteria cultured from fish guts in the Gulf of Oman. Luminescence, 161-168.

Miller, S.D., Haddock, S.H.D., Elvidge, C.D., Lee, T.F., 2005. Detection of a bioluminescent milky sea from space. PNAS 102, 14181-14184.

Musa, N., Wei, L.S., Wee, W., 2008. Phenotypic and Genotypic Characteristics of Vibrio Harveyi Isolated from Black Tiger Shrimp (Penaeus Monodon). World Applied Sciences Journal 3, 885902.

Ortigosa, M., Garay, E., Pujalte, M.J., 1994. Numerical Taxonomy of Vibrionaceae Isolated from Oysters and Seawater Along an Annual Cycle. Systematic and Applied Microbiology 17, 216-225.

Pang, L., Zhang, X.-H., Zhong, Y., Chen, J., Li, Y., Austin, B., 2006. Identification of Vibrio harveyi using PCR amplification of the toxR gene. Letters in Applied Microbiology 43, 249-255.

Pass, D.A., Dybdahl, R., Mannion, M.M., 1987. Investigations into the causes of mortality of the pearl oyster, Pinctada maxima (Jamson), in Western Australia. Aquaculture 65, 149-169.

Pujalte, M.J., Bobadilla, A.S., Álvarez-Pellitero, P., Garay, E., 2003a. Carriage of potentially fishpathogenic bacteria in Sparus aurata cultured in Mediterranean fish farms. Diseases of Aquatic Organisms 54, 119-126. 
Pujalte, M.J., Ortigosa, M., Macián, M.C., Garay, E., 1999. Aerobic and facultative anaerobic 643 heterotrophic bacteria associated to Mediterranean oysters and seawater. International 644 Microbiology 2, 259-266.

Pujalte, M.J., Sitja-Bobadilla, A., Macian, M.C., Belloch, C., Alvarez-Pellitero, P., Perez-Sanchez, J., Uruburu, F., Garay, E., 2003b. Virulence and molecular typing of Vibrio harveyi strains isolated from cultured dentex, gilthead sea bream and European sea bass. Systematic and Applied Microbiology 26, 284-292.

650

Ramesh, A., Loganathan, B.G., Venkateswaran, K., 1990. Ecological dynamics of marine luminous bacteria. Journal of Basic Microbiology 30, 689-703.

Robertson, P.A.W., Calderon, J., Carrera, L., Stark, J.R., Zherdmant, M., Austin, B., 1998. Experimental Vibrio harveyi infections in Penaeus vannamei larvae. Diseases of Aquatic Organisms 32, 151-155.

Rodgers, C.J., Furones, M.D., 1998. Disease Problems in Cultured Marine Fish in the Mediterranean. Fish Pathology 33, 157-164.

Sawabe, T., Inoue, S., Fukui, Y., Yoshie, K., Nishihara, Y., Miura, H., 2007. Mass Mortality of Japanese Abalone Haliotis discus hannai Caused by Vibrio harveyi Infection. Microbes and Environments 22, 300-308.

Scarano, C., Spanu, C., Ziino, G., Pedonese, F., Dalmasso, A., Spanu, V., Virdis, S., De Santis, E.P., 2014. Antibiotic resistance of Vibrio species isolated from Sparus aurata reared in Italian mariculture. The new microbiologica 37, 329-337.

Sedano, J., Zorrilla, I., Moriñigo, M., Balebona, M., Vidaurreta, A., Bordas, M., Borrego, J., 1996. Microbial origin of the abdominal swelling affecting farmed larvae of gilt-head seabream, Sparus aurata L. Aquaculture Research 27, 323-333.

Suzuki, M.T., Giovannoni, S.J., 1996. Bias caused by template annealing in the amplification of mixtures of 16S rRNA genes by PCR. Applied and Environmental Microbiology 62, 625-630.

Toranzo, A.E., Magariños, B., Romalde, J.L., 2005. A review of the main bacterial fish diseases in mariculture systems. Aquaculture 246, 37-61.

Torky, H.A., Abdellrazeq, G.S., Hussein, M.M., Ghanem, N.H., 2016. Phenotypic and Molecular Characterization of Vibrio harveyi in Diseased Shrimp. Alexandria Journal of Veterinary Sciences 51 (2), 358-366.

Travers, M.-A., Le Goïc, N., Huchette, S., Koken, M., Paillard, C., 2008. Summer immune depression associated with increased susceptibility of the European abalone, Haliotis tuberculata to Vibrio harveyi infection. Fish \& Shellfish Immunology 25, 800-808.

Uribe, C., Folch, H., Enriquez, R., Moran, G., 2011. Innate and adaptive immunity in teleost fish: a review. Veterinarni Medicina 56, 486-503.

Vandenberghe, J., Thompson, F.L., Gomez-Gil, B., Swings, J., 2003. Phenotypic diversity amongst Vibrio isolates from marine aquaculture systems. Aquaculture 219, 9-20. 
693 Vandenberghe, J., Verdonck, L., Robles-Arozarena, R., Rivera, G., Bolland, A., Balladares, M., 694 Gomez-Gil, B., Calderon, J., Sorgeloos, P., Swings, J., 1999. Vibrios Associated with Litopenaeus 695 vannamei Larvae, Postlarvae, Broodstock, and Hatchery Probionts. Applied and Environmental 696 Microbiology 65, 2592-2597.

697

698 Vendramin, N., Zrncic, S., Padros, F., Oraic, D., Le Breton, A., Zarza, C., Olesen, N.J., 2016. Fish 699 health in Mediterranean Aquaculture, past mistakes and future challenges. Bulletin of the 700 European Association of Fish Pathologists 36, 38-45.

701

Whyte, S.K., 2007. The innate immune response of finfish - a review of current knowledge. Fish \& Shellfish Immunology 23, 1127-1151.

Zhang, X.-H., Austin, B., 2000. Pathogenicity of Vibrio harveyi to salmonids. Journal of Fish Diseases 23, 93-102.

Zorrilla, I., Arijo, S., Chabrillon, M., Diaz, P., Martinez-Manzanares, E., Balebona, M.C., Moriñigo, M.A., 2003a. Vibrio species isolated from diseased farmed sole, Solea senegalensis (Kaup), and evaluation of the potential virulence role of their extracellular products. Journal of Fish Disease 26, 103-108.

Zorrilla, I., Chabrillón, M., Arijo, S., Díaz-Rosales, P., Martínez-Manzanares, E., Balebona, M.C., 714 Moriñigo, M.A., 2003b. Bacteria recovered from diseased cultured gilthead sea bream (Sparus aurata L.) in southwestern Spain. Aquaculture 218, 11-20. 